\title{
Failed First Trimester Pregnancy Termination: Uterine Anomaly as Etiologic Factor
}

\author{
David R. Pennes, M.D.,' Richard A. Bowerman, M.D.,' Terry M. Silver, M.D.,' \\ and Steven J. Smith, M.D. ${ }^{2}$
}

\begin{abstract}
Failure of first trimester pregnancy termination is an uncommon, although potentially serious complication of attempted therapeutic abortion. We report our experience in four patients with unsuspected congenital uterine anomalies in whom attempted pregnancy termination procedures failed to completely ablate the products of conception. When dilatation and curettage fails to produce embryonic tissue, sonography is indicated to exclude ectopic gestation or uterine anomaly. In patients who are known to have anomalous uteri, intraoperative real-time guidance may increase the success of pregnancy termination procedures and decrease the incidence of retained products of conception. Indexing Words: Pregnancy, complication - Pregnancy, ultrasound · Uterus, ultrasound · Uterus, anomaly
\end{abstract}

Failure of first trimester pregnancy termination is an uncommon although potentially serious complication of attempted therapeutic abortion, occurring with an incidence of $0.018-4.2 \%$ of all such procedures. ${ }^{1-6}$ Delayed pregnancy termination, often until the second trimester, ${ }^{5}$ may necessitate a more hazardous termination procedure later in pregnancy. Furthermore, failure to successfully terminate a pregnancy is a source of embarrassment and potential litigation for the physicians performing the procedure ${ }^{5,6}$ as well as psychological trauma for the patient.

Causes of failure of early pregnancy termination include operator-dependent technical factors, unrecognized ectopic pregnancy, marked uterine anteversion or retroversion, uterine leiomyomata, and tortuous cervical canal. ${ }^{5-7}$ The presence of a congenital uterine anomaly has also been recognized as an occasional contributing factor in failure of pregnancy termination. ${ }^{3-7}$ We report our experience in the sonography of four recent pa-

From the 'Department of Radiology, University of Michigan Hospitals, Ann Arbor, Michigan and the ${ }^{2}$ Department of Radiology, Community Memorial General Hospital, LaGrange, Illinois

Address reprint requests to David R. Pennes, M.D., Department of Radiology, University of Michigan Hospitals, Taubman Center 2910K/0326, 1500 E. Medical Center Drive, Ann Arbor, MI 48109-0326 313/936-4359 tients with unsuspected congenital uterine anomalies who had failure of first trimester pregnancy termination procedures. In one case, intraoperative sonographic guidance was required for even partial evacuation of the products of conception.

\section{CASE HISTORIES}

\section{Case 1}

A 24-year-old G-1, P-0 patient with myositis ossificans progressiva was presumed five weeks pregnant based on the date of her last menstrual period. Dilatation and curettage was performed; however, no products of conception were obtained. Sonography, first performed following the procedure, demonstrated a bicornuate uterus with an intact gestational sac containing a 10-11 week fetus in the left horn (Fig. 1A). Repeat dilatation and curettage was then performed with intraoperative sonographic guidance. Because of the technical difficulty of the procedure, the gestational sac could only partially be evacuated (Fig. 1B). The patient later spontaneously aborted the remaining products of conception without complication.

\section{Case 2}

A 23-year-old G-1, P-0 patient underwent dilatation and curettage for termination of a six-week 


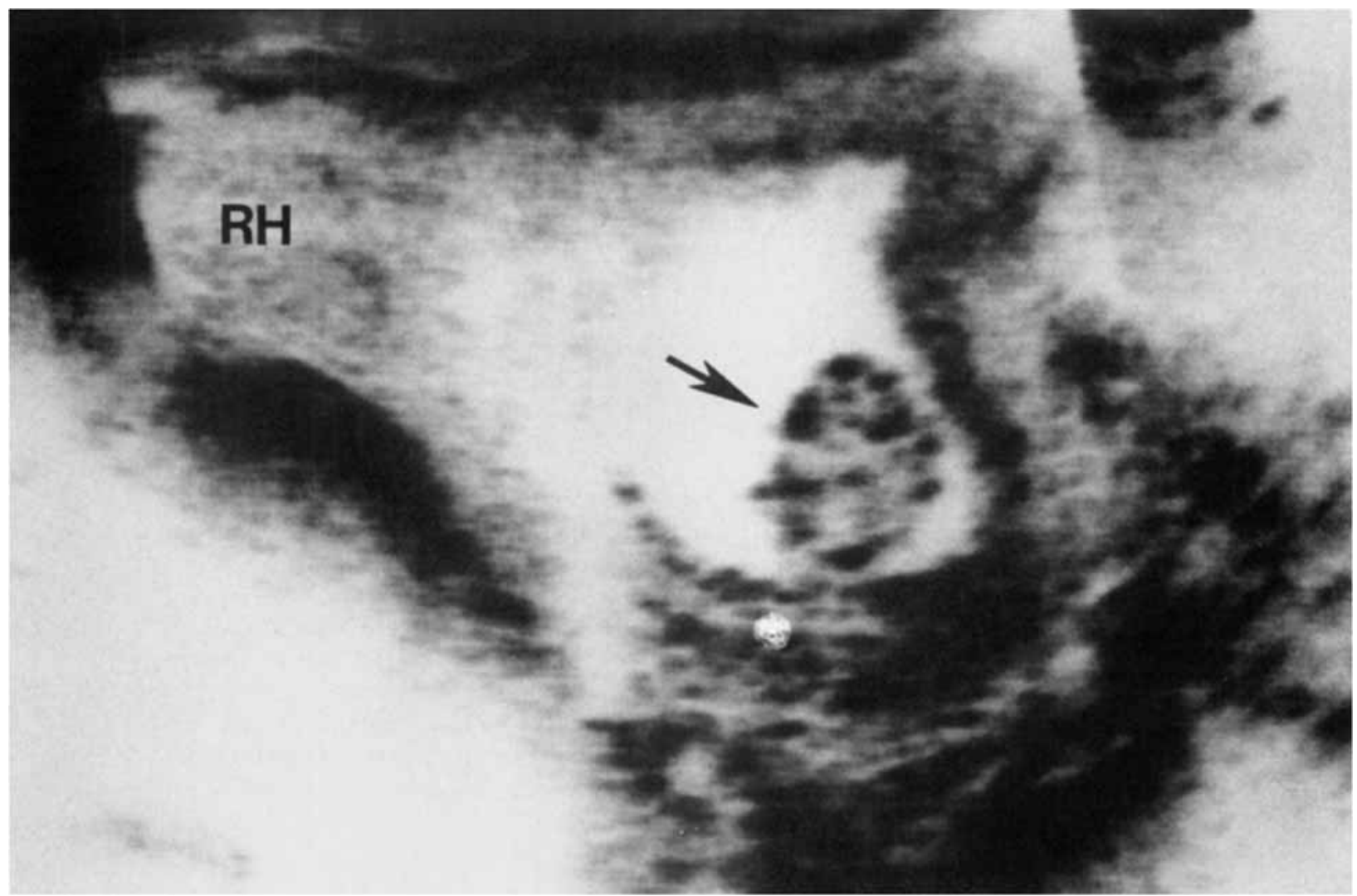

A.

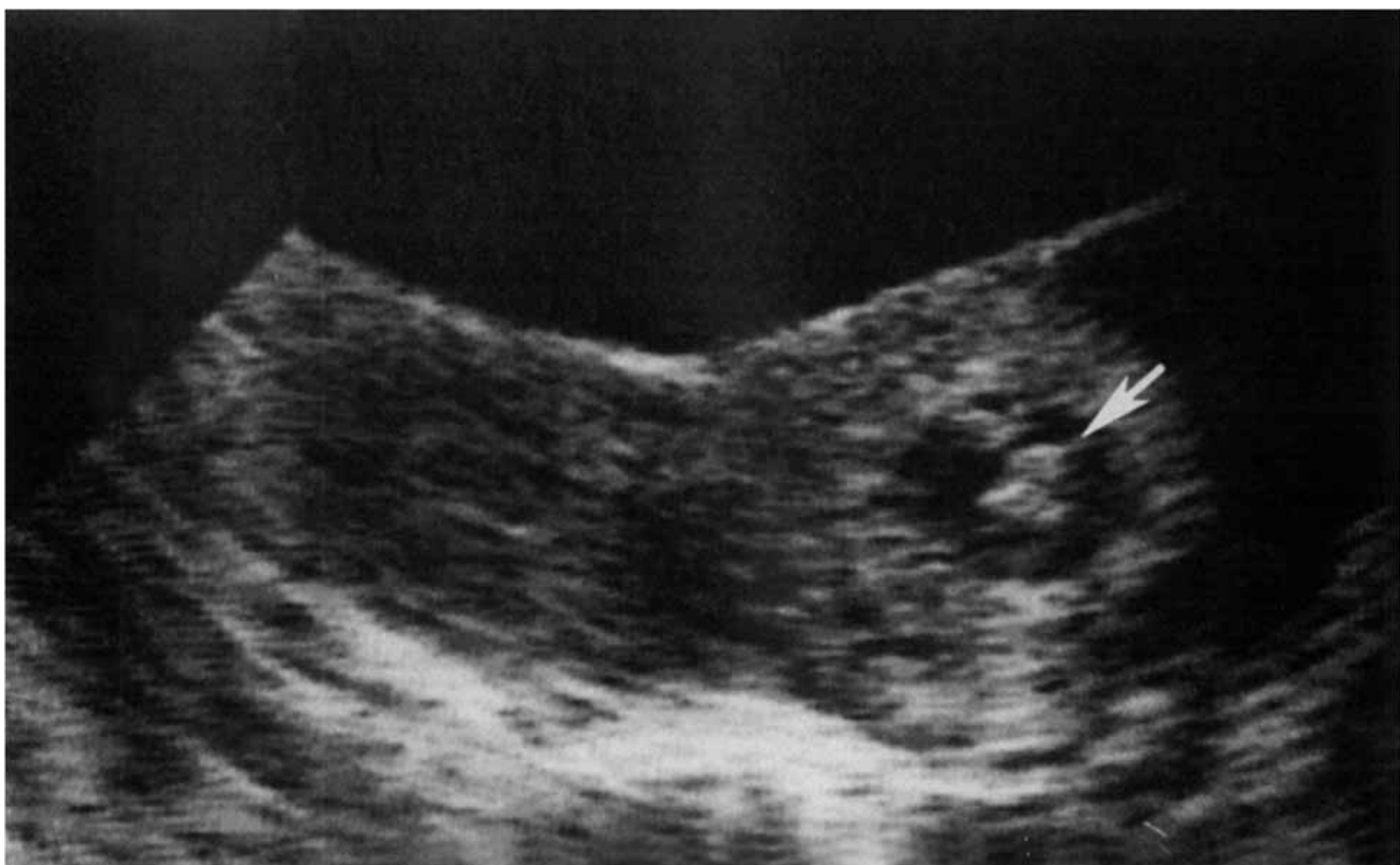

B.

FGURE 1, Case 1. Failure of pregnancy termination in patient with bicornuate uterus. A. Transverse scan. Uterus has a bilobed contour, with the pregnancy in the left horn, and decidual reaction in the non-gravid right horn. Image was obtained following dilatation and curettage, demonstrating the intact gestational sac containing a 10-11 week fetus (arrow). RH-right horn. B. Transverse scan following a repeat dilatation and curettage with intraoperative sonographic guidance demonstrates the bilobed contour of the uterine fundus, representing both horns of the bicornuate uterus. A portion of the conceptus (arrow) remains in the left horn. 


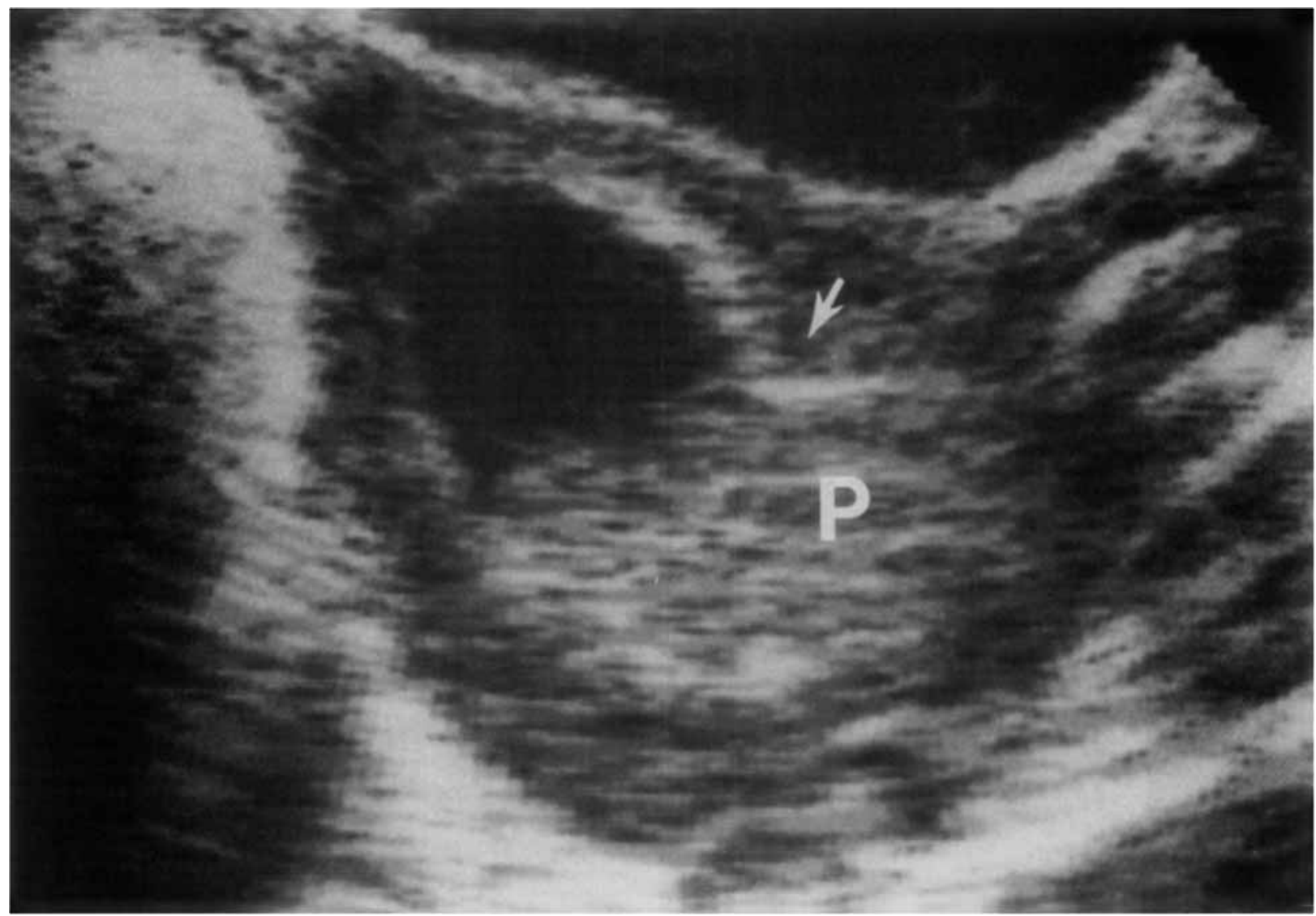

FIGURE 2, Case 2. Angled transverse scan. Following incomplete uterine evacuation, echogenic debris representing retained products of conception (P) remain in the left horn of a subseptate uterus. The short, broad septum characteristic of a subseptate uterus is indicated (arrow).

gestation. Because of continued vaginal bleeding during the next two weeks, an initial sonogram was performed, demonstrating retained products of conception in the left horn of a subseptate uterus (Fig. 2). These findings were confirmed at hysteroscopy, at which time complete evacuation of the uterus revealed both viable and necrotic chorionic villi with gestational endometrium.

\section{Case 3}

A 20-year-old G-1, P-0 patient underwent obstetrical sonography which was believed to demonstrate an unruptured right adnexal ectopic pregnancy of eight-nine weeks gestational age. Dilatation and curettage yielded only a small amount of tissue, with no identifiable chorionic villi or products of conception. Immediate exploratory laparotomy demonstrated no ectopic gestation. Hysterotomy performed during the laparotomy, however, revealed a septate uterus with an intact gestational sac in the right horn (Fig. 3).

\section{Case 4}

A 23-year-old woman underwent dilatation and curettage for pregnancy termination, at which time no products of conception were obtained. An initial sonogram after the procedure (Fig. 4) demonstrated a seven-week intrauterine gestation in the right horn of a bicornuate uterus. Despite knowledge of the uterine anomaly and the location of the gestational sac, a second dilatation and curettage procedure also failed to evacuate the products of conception. Successful evacuation was performed on the third attempt.

\section{DISCUSSION}

Uterine anomalies occur in approximately $0.1-0.5 \%$ of all women. ${ }^{8-10}$ The most recent Communicable Disease Center survey of abortion surveillance reported that in 1978 , more than 1 million first trimester pregnancy termination procedures were performed in the United States, ${ }^{11}$ suggesting that 1,000 to 5,000 women with anomalous uteri 


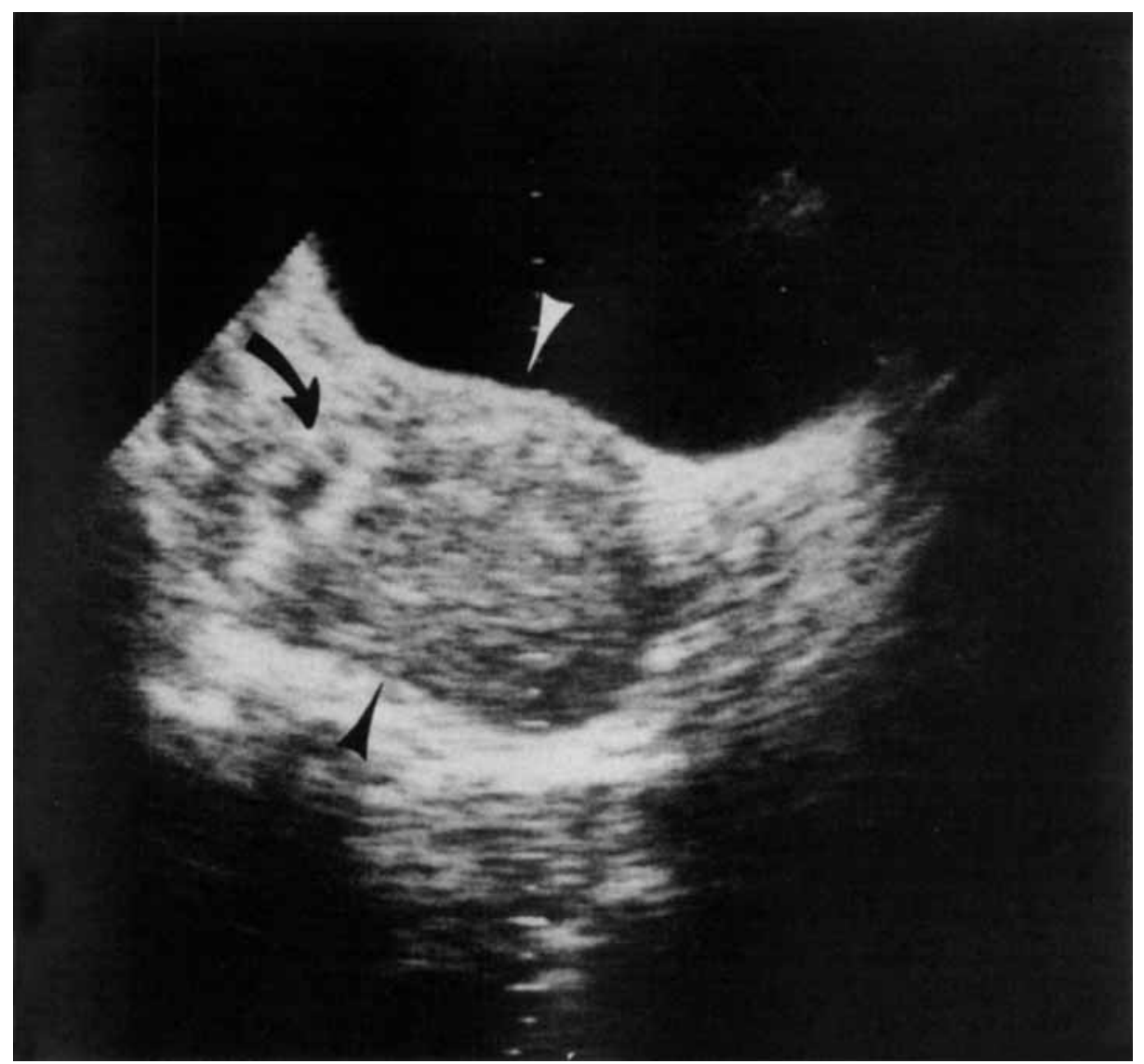

FIGURE 3, Case 3. Transverse scan. Gestational sac (arrow) is in the right horn of a subseptate uterus. Findings were misinterpreted as a right ectopic gestation. In this early gestation, the short, broad septum characteristic of a subseptate uterus is not identifiable as in Figure 2; however, the approximate plane of the septum is indicated (arrowheads).

underwent first trimester pregnancy termination procedures in that year alone.

In clinical series of patients who had failure of first trimester pregnancy termination, between $4.3 \%$ and $28 \%$ of such patients were found to have a congenital uterine anomaly as a contributing factor in the failure of the pregnancy termination procedures. $^{3,5-7}$

The sonographic findings of uterine anomalies are most apparent on transverse images and consist of: a bilobed uterine contour (Figs. 1,4) (or an anterior and/or posterior uterine indentation), an eccentrically located gestational sac (Figs. 1-4) and echogenic endometrial debris, representing decidual reaction, in the non-gravid horn ${ }^{12-14}$ (Figs. 1A,4).

Previous reports of uterine anomalies in patients with failed first trimester abortion included patients with bicornuate uteri, ${ }^{4,5}$ septate uteri, ${ }^{7}$ and unilateral blind horn. ${ }^{7}$ Although it is doubtful that ultrasound could differentiate this latter entity from the more common unilateral pregnancy in a bicornuate uterus, the significance of unilateral blind horn is that laparotomy with excision of the horn is required for pregnancy termination. It should be noted that in addition to ongoing pregnancy, partial ablation of the gestation, as in case 1 , is attendant with the additional problems of retained products of conception: potential infection and disseminated intravascular coagulation. In addition to complications relating to pregnancy termination, patients with uterine anomalies are recognized as having a higher risk of uterine perforation during the performance of dilatation and curettage, especially during the puerperium. ${ }^{15,16}$

Intraoperative sonographic guidance ${ }^{17}$ was useful in Case 1, in part because of extreme patient rigidity secondary to the presence of myositis ossificans progressiva, which made the procedure technically very difficult, but also due to the presence of a bicornuate uterus. It is possible that intraoperative sonographic guidance could have been useful in case 4 , in directing the evacuation cannula during the second evacuation attempt. 


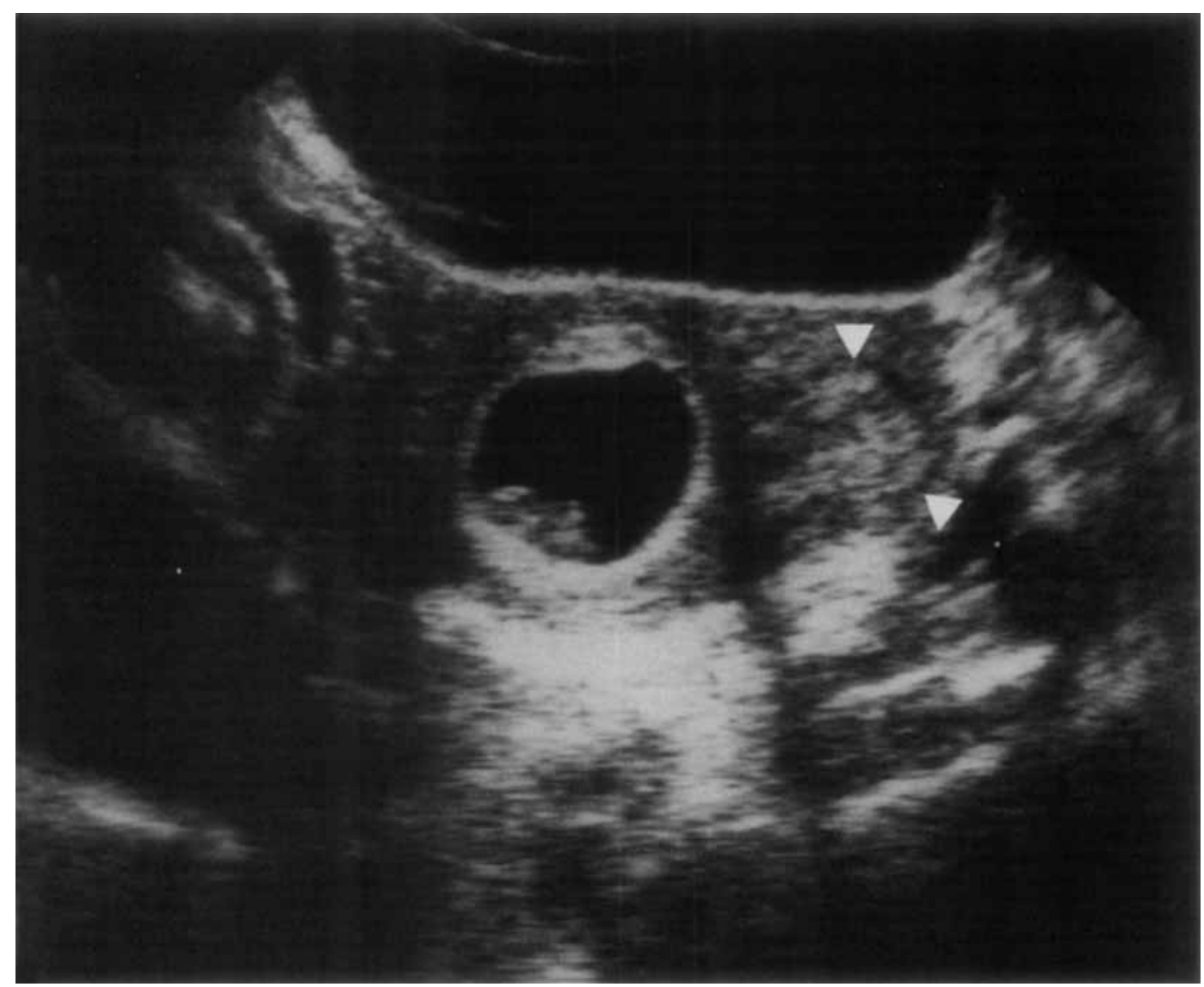

FIGURE 4, Case 4. Transverse sonogram following dilatatiori and curettage demonstrates an intact gestational sac containing a 7-week embryo in the right horn of a bicornuate uterus. Decidual reaction (arrowheads) is present in the non-gravid left horn.

Careful sonography and an awareness of the sonographic findings of early pregnancy in anomalous uteri should improve the detection of these anomalies. Recognition of such anomalies will also allow differentiation of those patients requiring repeat dilatation and curettage from those requiring laparotomy, as in the presence of a blind uterine horn or ectopic gestation. Our sonographic misinterpretation of a pregnancy in one horn of a septate uterus as an ectopic gestation (Case 3) resulted in an unnecessary laparotomy.

Although it is not technically and economically feasible to perform sonograms in all patients prior to planned first trimester abortion, in those patients in whom the procedure has failed sonography is indicated before repeating the procedure to exclude ectopic pregnancy or uterine anomaly. In patients who are known to have anomalous uteri, intraoperative real-time sonographic guidance may increase the success of the procedure and decrease the incidence of retained products of conception and uterine perforation.

\section{REFERENCES}

1. Walton LA: Immediate morbidity on large abortion service. NY State J Med 72:919, 1972.

2. Bozorgi N: Statistical analysis of first trimester pregnancy terminations in an ambulatory surgical center. Am J Obstet Gynecol 127:763, 1977.

3. Hodgson JE: Major complications of 20,248 consecutive first trimester abortions: Problems of fragmented care. Adv Planned Parenthood 9:52, 1975.

4. Hodgson JE, Portmann KC: Complications of 10,453 consecutive first trimester abortions: a prospective study. Am J Obstet Gynecol 120:802, 1974.

5. Fielding WL, Lee SY, Friedman EA: Continued pregnancy after first trimester abortion. Obstet Gynecol 52:56, 1978.

6. Kaunitz AM, Rovira EZ, Grimes DA, Schulz KF: Abortions that fail. Obstet Gynecol 66:533, 1985.

7. Valle RF, Sabbagha RE: Management of first trimester pregnancy termination failures. Obstet Gyencol 55:625, 1980.

8. Woolf RB, Allen WM: Concomitant malformations: the frequent simultaneous occurrence of congenital 
malformations of the reproductive and urinary tracts. Obstet Gyencol 2:236, 1953.

9. Wiersma AF, Peterson LF, Justema EJ: Uterine anomalies associated with unilateral renal agenesis. Obstet Gyencol 47:654, 1976.

10. Benirschke $K$ : Congenital anomalies of the uterus with emphasis on genetic causes, in: HJ Norris, AT Hertig, MR Abell (eds): The Uterus. Baltimore, Williams and Wilkins, 1973, p 68.

11. Centers for Disease Control (CDC): Abortion Surveillance, 1978. Atlanta, Georgia, November 1980.

12. Pennes DR, Bowerman RA, Silver TM: Congenital uterine anomalies and associated pregnancies: findings and pitfalls of sonographic diagnosis. J Ultrasound Med 4:531, 1985.

13. Malini S, Valdes C, Malinak R: Sonographic di- agnosis and classification of anomalies of the female genital tract. J Ultrasound Med 3:397, 1984.

14. Jones TB, Fleischer AC, Daniell JF, Lindsey AM, James AE: Sonographic characteristics of congenital uterine anomalies and associated pregnancy. JCU 8:435, 1980.

15. Radman HM, Korman W: Uterine perforation during dilatation and curettage. Obstet Gynecol 21: $210,1963$.

16. Deasy $\mathrm{P}$, Anderson GV: Uterine perforation as a complication of dilatation and curettage and its management. West J Surg Obstet Gynecol 68:294, 1960.

17. Goldenberg RL, Davis RO, Hill D: The use of realtime ultrasound as an aid during difficult therapeutic abortion procedures. Am J Obstet Gynecol 148:826, 1984. 